\title{
PRECIS-2: a tool to improve the applicability of randomised controlled trials
}

\author{
Kirsty Loudon ${ }^{1 *}$, Merrick Zwarenstein², Frank Sullivan ${ }^{1}$, Peter Donnan ${ }^{1}$, Shaun Treweek ${ }^{3}$ \\ From 2nd Clinical Trials Methodology Conference: Methodology Matters \\ Edinburgh, UK. 18-19 November 2013
}

\section{Background}

RCTs are considered the most rigorous design to evaluate the effectiveness of different interventions but have generalizability issues. Our tool, PRECIS, could help trialists consider the effects of their design decisions on the applicability of their results in clinical settings.

\section{Aim}

To produce an improved and validated version of PRECIS.

\section{Methods}

Phase 1 involved brainstorming and a two-round Delphi survey of authors who cited PRECIS. Phase 2 involved discussion of the Delphi results by experienced trialists and alternative versions of PRECIS-2 developed and user-tested. Phase 3 will evaluate the validity and reliability of the most promising PRECIS-2 candidate using a sample of $15-20$ trials rated by 15 other trialists.

\section{Results}

Brainstorming sessions identified the PRECIS presentation (a wheel), lack of a scoring system and domain weighting as issues for exploration in the Delphi process. Thirty four completed responses from 90 invitees were received in Round 1 of the Delphi; Round 2 involved 23 individuals (response rate $82 \%$ ). $45 \%$ selected a 1-5 Likert scale, $56.5 \%$ wanted to use a table (to justify decisions) and a PRECIS wheel, 26\% were in favour of weighting domains. Suggestions for extra domains included: recruitment process for participants and integration of the intervention into the healthcare system. An expert panel in Toronto used the Delphi suggestions to help create alternative versions of PRECIS-2 for user-testing in spring 2013.

${ }^{1}$ University of Dundee, Dundee, Scotland, UK

Full list of author information is available at the end of the article

\section{Conclusions}

PRECIS can be improved by the addition of a Likert scale and additional domains. We expect to have a validated PRECIS-2 by the beginning of 2014 .

\section{Authors' details}

'University of Dundee, Dundee, Scotland, UK. ${ }^{2}$ Western University, London, Ontario, Canada. ${ }^{3}$ University of Aberdeen, Aberdeen, Scotland, UK.

Published: 29 November 2013

doi:10.1186/1745-6215-14-S1-O28

Cite this article as: Loudon et al.: PRECIS-2: a tool to improve the applicability of randomised controlled trials. Trials 2013 14(Suppl 1):028
Submit your next manuscript to BioMed Central and take full advantage of:

- Convenient online submission

- Thorough peer review

- No space constraints or color figure charges

- Immediate publication on acceptance

- Inclusion in PubMed, CAS, Scopus and Google Scholar

- Research which is freely available for redistribution
C Biomed Central 